\title{
Seed viability of alpine species: variability within and
} among years

\author{
JEANNE C. CHAMBERS
}

\section{Abstract}

Percent of seeds filled for alpine grasses and seed viability and longevity for alpine grasses and forbs with different life history and physiological traits were evaluated for seeds collected in 1983, 1984, 1985, and 1986 on the Beartooth Plateau, Mont. Significant $(p<0.001)$ differences existed in the percent of seeds filled for grass species and in the seed viability of both grass and forb species among years. The high variability in seed viability among years is attributed to the severe and unpredictable nature of the environment. Seed viability differed among species within most years. In general, grass species had lower and more variable seed viability than forb species. Low seed viability years for the grass species coincided with low seed fill years, indicating poor seed development. Longevity of seeds collected in 1983 varied among species and was related to seed characteristics and the overall life history and physiological traits of individual species. Seed longevity of species with life history and physiological traits typical of late seral species was shorter than that of species with traits typical of early seral species.

Key Words: alpine ecosystem, seed viability, seed longevity, percent seeds filled

The quantity and quality of seeds produced by tundra species vary both temporally and spatially. Production of viable seed is dependent upon the previous and current year's growing seasons and, in certain species, on the growing season of the following year. In most alpine species growth of the inflorescence is initiated 1 or even 2 seasons prior to flowering (Spomer 1964, Billings and Mooney 1968, Savile 1972, Billings 1974). In dwarf braya (Brayia humilis), an arctic species in northeast Greenland, fruits do not mature the year of flowering but become dormant during the winter and ripen the following summer (Sorenson 1941). Viable seed production of species such as alpine sorrel (Oxyria digyna) decreases with both latitude and altitude on a global scale, (Billings and Mooney 1968), and also decreases with increasing environmental severity for individual species on a local scale. Species that produce large numbers of seeds in meadows may produce few or no seeds on wind-exposed or late-melting snowbank sites (Bliss 1956). Although limited information exists on the spatial variability of viable seed production, almost no empirical data exist on the temporal variability of seed production within distinct communities or among species.

Seed longevity, viz., viability of an individual seed population over time, differs among early and late successional species within the same community in more temperate environments. Early successional species frequently have longer lived seeds than late successional species. This allows seeds of early successional species to survive for longer periods in the soil (Harper et al. 1970; Grime 1977, 1979). Successional processes are less apparent in alpine ecosystems than in more temperate systems (MacMahon 1980),

\footnotetext{
Author is plant ecologist, USDA Forest Service, Intermountain Research Station, Forestry Sciences Laboratory, 860 North 1200 East, Logan, Utah 84322-8000.

This manuscript benefited from reviews by R.W. Brown, J.A. Young, N.L. Shaw, and B.A. Roundy. K. Dwire and J. Binder provided technical assistance.

The use of trade or firm names in this paper is for reader information and does not imply endorsement by the U.S. Department of Agriculture of any product or service. Manuscript accepted 27 December 1988.
}

but several researchers have recognized distinct successional sequences (Churchill and Hanson 1958, Bliss 1962, Webber and Ives 1978, Roach and Marchand 1984). Successional pathways within disturbed alpine ecosystems are dependent upon the relationship of species' physiological and life history traits with the physical environment (MacMahon 1981, Huston and Smith 1987). Earlier studies examined seed germination characteristics (Chambers et al. 1987a), nutrient responses (Chambers et al. 1987b), and seedling establishment (Chambers 1987) of alpine species with physiological and life history traits typical of early or late seral species in more temperate systems. Knowledge of the variability in seed viability of these alpine species can further increase our understanding of successional processes in these ecosystems.

Reclamation of disturbed alpine ecosystems is almost totally dependent upon the use of adapted native species (Brown et al. 1978). Past revegetation efforts in these areas have focused on grass species that occur naturally in abundance on disturbed alpine areas (e.g., Brown et al. 1976). Inclusion of species with different life forms and successional affinities in alpine revegetation can increase species diversity and accelerate successional processes. Seeds of these species are seldom available on a commercial basis and are often collected near the disturbed area immediately prior to revegetation. Information about variability in seed viability and longevity of different alpine species can indicate optimal methods of seed collection and storage.

This study evaluated differences in seed viability and longevity of alpine species with different life history and physiological traits. The question addressed was: Does seed viability and longevity of alpine species that differ in life history and physiological traits but that coexist within the same community vary among species or years?

\section{Methods}

The species studied are widely distributed throughout the central and southern Rocky Mountains and occur naturally within Geum turf vegetation on both early and late seral areas (Johnson and Billings 1962, Chambers et al. 1984). They included 5 forbs: Ross' avens (Geum rossii [R. Br.] Ser.), Rocky Mountain sage (Artemisia scopulorum Gray), sticky sky pilot (Polemonium viscosum Nutt.), sibbaldia (Sibbaldia procumbens L.), and blueleaf cinquefoil (Potentilla diversifolia Lehm.). They also included 3 grasses: Idaho fescue (Festuca idahoensis Elmer), tufted hairgrass (Deschampsia cespitosa [L.] Beauv.), and alpine reedgrass (Calamagrostis purpurascens $\mathrm{R}$. Br.). Ross' avens is a dominant species in late seral Geum turf vegetation, but it is also a colonizer on weathered porphyry intrusions or wind-eroded areas characterized by gravel mulch. Rocky Mountain sage, sticky sky pilot, and Idaho fescue are abundant in late seral Geum turf vegetation and are infrequent colonizers. Blueleaf cinquefoil, sibbaldia, and alpine reedgrass are relatively low in abundance in both Geum turf and Deschampsia meadow vegetation and are active colonizers in a wide range of disturbed areas. Tufted hairgrass occurs in low density in late seral Geum turf vegetation, is a n active colonizer on numerous disturbed areas, and is the dominant in Deschampsia 


\section{Idaho \\ fescue \\ Tufted \\ hairgrass}

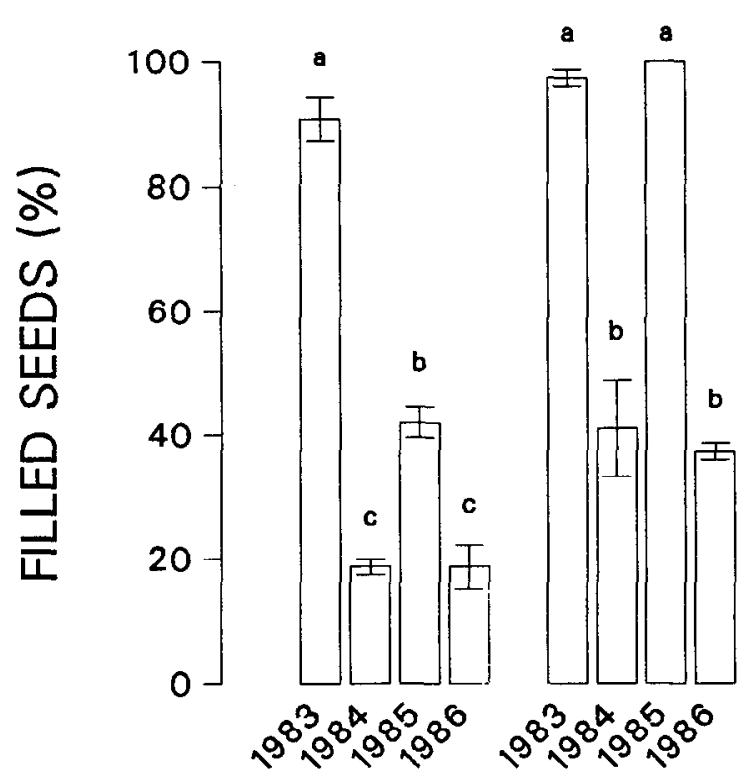

\section{YEAR COLLECTED}

Fig. 1. Percent filled seeds of 2 grass species collected in 1983, 1984, 1985, and 1986 on the Beartooth Plateau, Mont. Values are means and error bars represent $\pm 1 S E$. SEs too small to illustrate do not appear on the graph. Unlike letters indicate significant differences among years within species $(\mathrm{p}<0.05)$. meadow vegetation.

Seeds were collected 9 September 1983, 14 September 1984, 22 August 1985, and 10 September 1987, from disturbed and undisturbed areas within the Geum turf vegetation type on the Beartooth Plateau, Montana (lat. $45^{\circ} 00^{\prime} \mathrm{N}$, long. $109^{\circ} 30^{\prime} \mathrm{W}$; elevation $3,050 \mathrm{~m}$ ). The disturbed area was a 30 -year old gravel barrow pit with loamy sand soils and less than $15 \%$ vegetation cover. The adjacent undisturbed area had turf soils and vegetation cover greater than $90 \%$. Seeds were inspected in the field prior to collection and hand harvested when seeds of the majority of the species were filled. Differences among collection dates across years reflect differences in growing seasons and dates of seed maturity. Following harvest, seeds were allowed to dry for 2 weeks before threshing and cleaning. The seeds were then stored dry at 1 to $2^{\circ} \mathrm{C}$ and 70 to $85 \%$ relative humidity until initiation of each year's viability tests.

Three replications of 100 seeds of each species were used for determining percent seeds filled and viability. Percent fill of grass seeds was determined prior to viability testing. Seeds were scored as filled if they contained a well-developed, filled caryopsis. Only filled grass seeds were used in the viability tests. Because the seeds of all forb species appeared to be filled at the time of collection, no attempt was made to select forb seeds for the viability tests based upon filled seeds.

Viability of seeds from each of the different collection dates was evaluated approximately 6 months after the most recent collection date using a $1 \%$ aqueous solution of tetrazolium (2, 3, 5-triphenyl tetrazolium chloride) (USDA, Forest Service 1974). Seeds were soaked in distilled water for $18 \mathrm{~h}$, the seed coats were sliced with a razor or pierced with a needle, and the seeds were immersed in tetrazolium. After a 48-h dark incubation at $30^{\circ} \mathrm{C}$, seeds with completely stained embryos were scored as viable.

Differences among years for each of the different collection dates and differences within years for individual collection dates

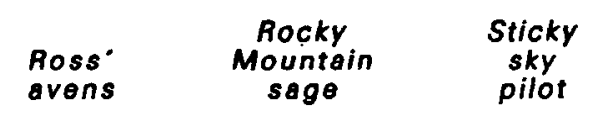

b

b

o

$\begin{array}{cc}\text { Idaho } & \text { Tufted } \\ \text { fescue } & \text { hairgrass }\end{array}$

$\theta$

d

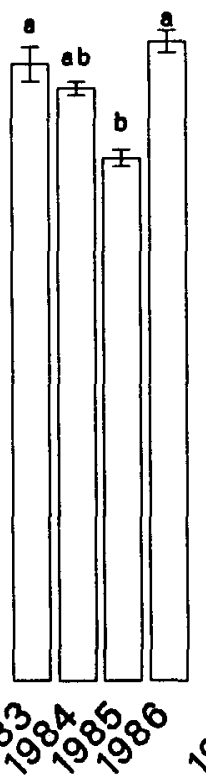

a

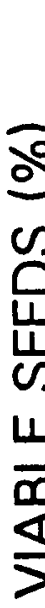

\section{YEAR COLLECTED}

Fig. 2. Viability of seeds of alpine species collected during 4 consecutive years on the Beartooth Plateau, Mont., and tested for viability the year of collection. Values are means and error bars represent \pm 1 SE. SEs too small to illustrate do not appear on the graph. Unlike letters indicate significant differences in seed viability among species for the first row of letters and among years within species for the 2nd row of letters (p<0.05). 
were evaluated with 2-way analysis of variance (ANOVA). To account for repeated measures in the analysis of seeds that were collected on the same date and tested over time, years were treated as a split-plot and conservative degree of freedom were used in the F-tests. Differences in seed longevity among species were determined from analysis of the change in seed viability in 1984, 1985, and 1986 from average initial 1983 values. Due to low numbers of seeds collected for alpine reedgrass, seeds of this species were included only in the longevity tests. All analyses were executed on arcsine transformed data. Mean comparisons were performed using Fisher's protected LSDs.

\section{Results}

Percent of seeds filled of Idaho fescue and tufted hairgrass varied greatly from year-to-year $(p<0.001)$ (Fig. 1). During the 4 years, differences in percent of seeds filled between high and low years were 72 and $63 \%$ for Idaho fescue and tufted hairgrass, respectively. Both species exhibited the same patterns of seed fill in response to environmental conditions. They had significantly higher seed fill in 1983 and 1985 than in 1984 and $1986(p<0.05)$. Seed fill of Idaho fescue was statistically lower than that of tufted hairgrass in 1984, 1985, and 1986.

Significant differences in seed viability existed among collection years for seeds tested during the year following collection $(p<0.001)$ (Fig. 2). Seed viability averaged over species was $90.1,50.1,53.1$, and $64.5 \%$ for $1983,1984,1985$, and 1986, respectively. Each year differed statistically from each of the other years, except for 1984 and $1985(p<0.05)$.

Seed viability was also highly variable among species for different collection dates $(p<0.001)$ (Fig. 2). Sticky sky pilot had consistently high viability among years and had the highest average viability. No differences existed in average viability of the forbs, Ross' avens, Rocky Mountain sage, or sibbaldia. The 2 grasses exhibited lower average viability than the forbs. In general, viability of tufted hairgrass was greater than that of Idaho fescue, reflecting the pattern seen for percent of seeds filled. Blueleaf cinquefoil had values intermediate between the other forbs and the grasses.

A strong species by year interaction existed for the different collection dates $(p<0.001)$, indicating that differences in seed viability among years were not consistent among species (Fig. 2). The highest viability for most species was in 1983, but during subsequent years no distinct patterns existed. The lowest seed viability of seeds tested the first year after collection occurred in 1984 for the grasses, but in 1985 for many of the forbs. The magnitude of variation in seed viability of the grasses was greater than that of the forbs.

Seeds of all species except sticky sky pilot that were collected in 1983 and tested for 4 consecutive years showed large decreases in seed viability over time $(p<0.001)$ (Fig. 3). Seed viability averaged over species was $86.9,67.5,62.1$, and $36.4 \%$ for $1984,1985,1986$, and 1987, respectively. Each year differed statistically from each of the other years $(p<0.05)$. The greatest decreases in seed viability occurred between 1984 and 1985 and between 1986 and 1987. Significant differences existed among species $(p<0.001)$. Sticky sky pilot had no significant change in seed viability after 4 years. These results paralleled the consistently high viability observed for this species for different collection dates. Ross' avens exhibited large, significant, yearly decreases in seed viability $(p<0.05)$. The remainder of the species exhibited yearly declines that were intermediate between these 2 species. A species by year interaction $(p<0.01)$ existed because the differences in seed viability among years were not consisted among species.

Distinct differences in seed longevity among years and among species emerged from analysis of the change in seed viability between the 1 st and subsequent test dates $(p<0.001)$ (Table 1). Sticky sky pilot exhibited no significant change in seed viability and appeared to have the longest-lived seeds $(p<0.05)$. Ross'avens and Rocky Mountain sage exhibited the largest changes in seed viability, indicating that these forbs have the shortest-lived seeds.

$\begin{array}{ccc}\text { Ross } & \begin{array}{c}\text { Rocky } \\ \text { Mountain } \\ \text { sagens }\end{array} & \begin{array}{c}\text { Sticky } \\ \text { sky } \\ \text { silot }\end{array}\end{array}$

d

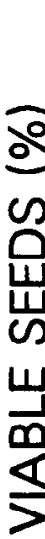

$\frac{2}{30}$

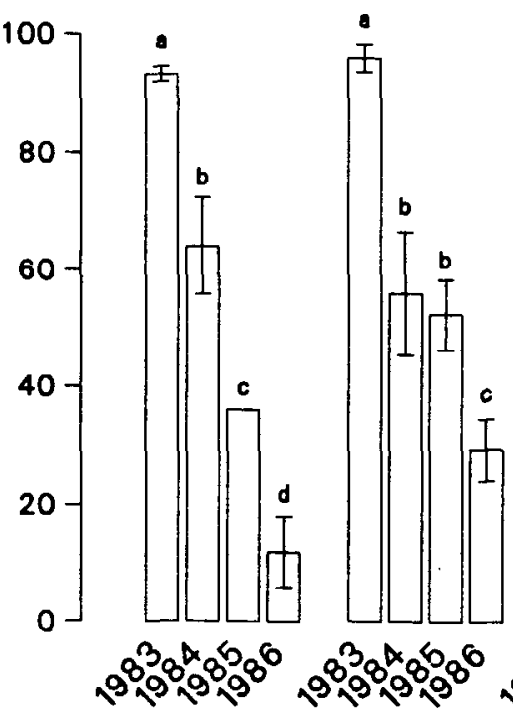

$\mathbf{a}$

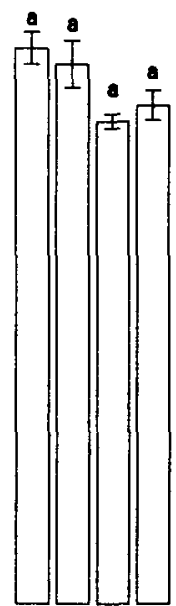

$3 \times 50$

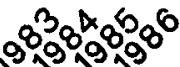

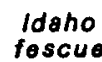

$c$
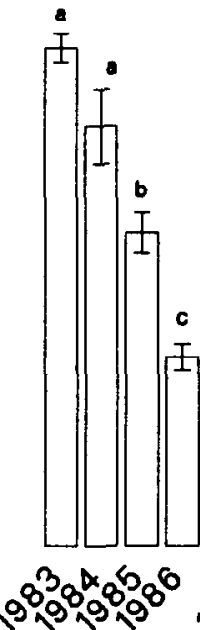

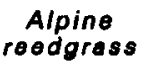

cd

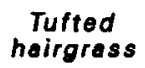

cd
Sibbaldia

C

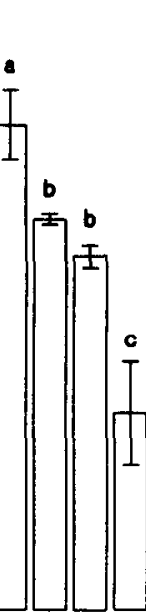

Blueleaf cinquofoil
0

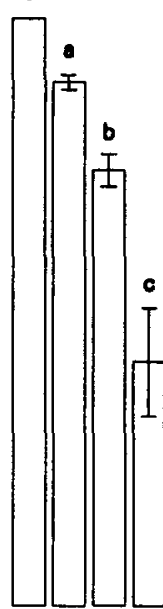

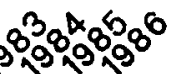
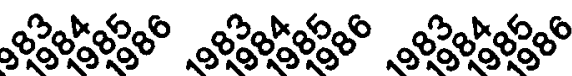

\section{YEAR TESTED}

Fis. 3. Viability of seeds of alpine species collected in 1983 on the Beartooth Plateau, Mont., placed into cold storage, and tested for viability for 4 consecutive years. Values are means and error bars represent $\pm 1 S E$. SEs too small to illustrate do not appear on the graph. Unlike letters indicate significant differences in seed viability among species for the first row of letters and among years within species for the 2 nd row of letters ( $\mathrm{p}<0.05$ ). 
Table 1. Change in percent viabillty among Intibil and subsequent test dates for seeds of alpine species collected September 1983 on the Beartooth Plateau, Mont.

\begin{tabular}{lccc}
\hline \hline Species & 1984 & 1985 & 1986 \\
\hline Ross' avens & $29.5 \pm 8.4^{1} \mathrm{a}^{2}$ & $57.3 \pm 0.1 \mathrm{~b}$ & $81.3 \pm 6.1 \mathrm{c} \mathrm{e}^{3}$ \\
Rocky Mountain & $40.0 \pm 10.6 \mathrm{a}$ & $43.7 \pm 6.1 \mathrm{a}$ & $66.7 \pm 5.2 \mathrm{~b}$ de \\
$\quad$ sage & & & \\
Sticky sky pilot & $5.4 \pm 2.7 \mathrm{a}$ & $12.4 \pm 1.2 \mathrm{a}$ & $9.7 \pm 2.5 \mathrm{a} \mathrm{a}$ \\
Idaho fescue & $13.3 \pm 6.4 \mathrm{a}$ & $31.6 \pm 3.5 \mathrm{~b}$ & $52.9 \pm 2.3 \mathrm{c} \mathrm{bcd}$ \\
Alpine reedgrass & $13.7 \pm 1.4 \mathrm{a}$ & $5.7 \pm 2.4 \mathrm{a}$ & $41.3 \pm 1.8 \mathrm{~b} \mathrm{~b}$ \\
Tufted hairgrass & $21.0 \pm 0.8 \mathrm{a}$ & $20.2 \pm 3.5 \mathrm{a}$ & $44.6 \pm 5.7 \mathrm{~b} \mathrm{bc}$ \\
Sibbaldia & $16.0 \pm 0.9 \mathrm{a}$ & $22.4 \pm 2.0 \mathrm{a}$ & $49.4 \pm 8.7 \mathrm{~b} \mathrm{bc}$ \\
Blueleaf cinquefoil & $10.7 \pm 1.3 \mathrm{a}$ & $25.7 \pm 2.8 \mathrm{~b}$ & $58.7 \pm 9.3 \mathrm{c} \mathrm{cd}$ \\
\hline
\end{tabular}

iValues are mean percent $\pm 1 \mathrm{SE}$.

2Unlike letters indicate significant differences $(p<0.05)$ in the change in seed viability among years for each species (rows).

${ }^{3}$ Unlike letters indicate significant differences $(p<0.05)$ in the change in seed viability among species at the end of the study (last column).

After 4 years the change in seed viability of blueleaf cinquefoil was intermediate between that of Rocky Mountain sage and the rest of the species. At the end of the study there were no statistical differences in seed longevity among the other species.

\section{Discussion}

The conditions under which seeds are stored affect the length of time that they remain viable. The moisture content of the seeds and the storage temperature are the 2 most important determinants of seed longevity (Copeland and McDonald 1985, Young and Young 1986). Maximum longevity of seeds of crop species is frequently obtained at seed moisture contents of 5 to $14 \%$ and seed storage temperatures of 1 to $5^{\circ} \mathrm{C}$ (Harrington 1973). Optimal storage temperatures for arctic and alpine seeds may be lower. Collections at Duke University of arctic and alpine seeds stored dry at $-18^{\circ} \mathrm{C}$ appear to retain their viability indefinitely (Billings and Mooney 1968). In this study storage temperatures were 1 to $2^{\circ} \mathrm{C}$ and seed moisture contents after 4 years in storage were $11,13,14,16,16,18$, and $18 \%$ for sibbaldia, blueleaf cinquefoil, Rocky Mountain sage, Idaho fescue, Ross' avens, sticky sky pilot, and tufted hairgrass, respectively. These conditions probably had little effect on the viability of seeds that were tested during the Ist year after collection. However, seed deterioration over time may have been greater than if seeds had been stored at the same temperature and lower seed moisture contents or at lower temperatures and lower seed moisture contents.

Seeds experience large fluctuations in both temperature and moisture content under natural conditions in the soil. Both temperatur ${ }^{\circ}$ and seed moisture content were constant in this study, and the rate of seed deterioration may not have been as great as in a natural system or may have been of a different nature. Regardless of storage conditions, the differences observed in seed viability and longevity among species are the result of innate seed properties and provide a relative measure of the differences among species in the soil seed reserves.

The high variability observed in reproduction in alpine ecosystems among years is largely attributable to environmental conditions (Billings and Mooney 1968, Billings 1974, Bliss 1985). Alpine ecosystems are characterized by growing seasons of only 60 to 90 days (Bliss 1985), growing season temperatures that average about $8^{\circ} \mathrm{C}$, and temperatures during the growing season that may fall below $0^{\circ}$ C. Despite substantial annual precipitation, e.g., $63 \mathrm{~cm}$ on Niwot Ridge in Colorado (Billings and Mooney 1968) and 120 $\mathrm{cm}$ on the Beartooth Plateau in Montana (Brown et al. 1978), most water arrives as winter snow, and soils may be dry late in the growing season. In this study significant differences existed in the seed maturity of grass species and in the seed viability of both grass and forb species for seeds collected in all 4 study years. Detailed weather measurements taken on the Beartooth Plateau in 1984 and 1985 at the seed collection areas showed large differences in the date of snow melt ( 3 weeks), the timing and amount of precipitation, and ambient and soil temperatures (Chambers 1987).

The relationship of species' life history and physiological traits with the environment is an important determinant of successful reproduction. Large differences in seed viability existed among species within most years. In general, seed viability of the grass species was lower and more variable than that of the forb species. Low seed viability years for the grass species coincided with low seed fill years, indicating poor seed development during those years. This may be attributed to slower phenological development of graminoids than of forbs growing within the same community (Bliss 1956, 1966; Fareed and Caldwell 1975). Many forb and shrub species on Mount Washington, New Hampshire, had completed 70 to $80 \%$ of their shoot elongation in 20 to $\mathbf{3 0}$ days, while graminoids continued leaf production and shoot elongation until late in the growing season (Bliss 1966). Similar results were observed for Rocky Mountain sage and Ross' avens versus tufted hairgrass in both Kobresia and Deschampsia meadow sites on Niwot Ridge in Colorado (Fareed and Caldwell 1975).

Seed longevity was highly variable among species and was related to seed characteristics and overall life history and physiological traits of individual species. Sticky sky pilot exhibited no significant decrease in seed longevity over 4 years despite relatively high seed moisture contents $(18 \%)$. Seeds of this species have a mucilaginous seed coat and strong innate dormancy mechanisms (Chambers et al. 1987a). These characteristics are associated with long life within the soil seed bank (Grime et al. 1981). Ross' avens and Rocky Mountain sage had significantly larger decreases in seed viability than the other species. Short-lived seeds are typical of late seral species in more temperate ecosystems (Harper et al. 1970, Grime 1979, Fenner 1985). Ross' avens and Rocky Mountain sage are abundant in late seral communities, are infrequent colonizers, and exhibit other characteristics typical of late seral species including slow growth rates (Chambers 1987). Sibbaldia and blueleaf cinquefoil had greater longevity than Ross' avens and Rocky Mountain sage. These species are frequent colonizers that exhibit several characteristics typical of early seral species including high growth rates and delayed germination of a significant portion of the seed population in both the field and laboratory (Chambers 1987; Chambers et al. 1987a, 1987b). Longevity did not differ among grass species or among the grasses and sibbaldia or blueleaf cinquefoil. Longevity of the grass species did not appear to be related to successional status.

Seed properties, including percent fill, viability, and longevity, can greatly affect the success of alpine reclamation efforts. Production of mature and viable seed in alpine ecosystems is not only variable among years but also among species within any given year. Seed collection in these ecosystems must be opportunistic to take advantage of good seed production years for different species. It may be necessary to harvest seeds 1 to several years prior to the reclamation of a disturbed area in order to obtain an adequate supply of viable seeds of the desired species. However, the effects of storage conditions on seed viability must also be considered (Copeland and McDonald 1985, Young and Young 1986). Species with characteristics typical of early seral dominants appear to have longer-lived seeds than species with characteristics typical of late seral dominants. These species could be expected to maintain comparatively higher viability under storage conditions similar to those in this study. Storage conditions that maximize longevity of crop seeds, i.e., 1 to $5^{\circ} \mathrm{C}$ and seed moisture contents of 5 to $14 \%$, may not be ideal for alpine species. It may be desirable to store seeds of alpine species at lower temperatures, i.e., $-18^{\circ} \mathrm{C}$, to increase their longevity. 
Numerous factors affect the seed maturity, viability, and longevity of species used in alpine reclamation. To ensure successful reclamation, it is necessary to collect seeds during good seed production years, determine that they are mature and viable, and store them under the proper conditions.

\section{Literature Cited}

Billings, W.D. 1974. Arctic and alpine vegetation: plant adaptations to cold summer climates. p. 403-444. In: J.D. Ives and R.G. Barry (eds.) Arctic and alpine environments. Methuen, London.

Billings, W.D., and H.A. Mooney. 1968. The ecology of arctic and alpine plants. Biol. Rev. 43:481-529.

Bliss, L.C. 1956. A comparison of plant development in microenvironments of arctic and alpine tundras. Ecol. Monogr. 26:303-337.

Bliss, L.C. 1962. Adaptations of arctic and alpine plants to environmental conditions. Arctic 15:117-144.

Bliss, L.C. 1966. Plant productivity in alpine microenvironments on Mt. Washington, New Hampshire. Ecol. Monogr. 36:125-155.

Bliss, L.C. 1985. Alpine. p. 41-65. In: B.F. Chabot and H.A. Mooney (eds.) Physiological ecology of North American plant communities. Chapman and Hall, New York.

Brown, R.W., R.S. Johnston, B.Z. Richardson, and E.E. Farmer. 1976. Rehabilitation of alpine disturbances: Beartooth Plateau, Montana. p. 58-73. In: R.H. Zuch and L.R. Brown (eds.) Proc.: High Altitude Revegetation Workshop No. 2. Infor. Ser. 21. Environ. Res. Center, Colorado State Univ., Fort Collins.

Brown, R.W., R.S. Johnston, and K. Van Cleve. 1978. Rehabilitation problems of arctic and alpine regions. p. 23-44. In: F.W. Schaller and P. Sutton (eds.) Reclamation of drastically disturbed lands. Amer. Soc. Agron., Madison, Wisc.

Chambers, J.C. 1987. Disturbed alpine ecosystems: seedling establishment of early and late seral dominant species. Ph.D. Diss., Utah State Univ. Logan.

Chambers, J.C., R.W. Brown, R.S. Johnston. 1984. Examination of plant successional stages in disturbed alpine ecosystems: a method of selecting revegetation species. p. 215-224. In: T.A. Colbert and R. Cuany (eds.) Proc.: High Altitude Revegetation Workshop No, 6. Infor. Ser. 53. Water Resources Res. Inst., Colorado State Univ., Fort Collins.

Chambers, J.C., J.A. MacMahon, and R.W. Brown. 1987a. Germination characteristics of alpine grasses and forbs: a comparison of early and late seral dominants with reclamation potential. Reclam. Reveg. Res. 6:235-249.

Chambers, J.C., J.A. MacMahon, and R.W. Brown. 1987b. Response of an early seral alpine grass and a late seral alpine forb to $\mathbf{N}$ and $\mathbf{P}$ availability: implications for revegetation. Reclam. Reveg. Res. 6:219-234.
Churchill, E.D., and H.C. Hanson. 1958. The concept of climax in arctic and alpine vegetation. Bot. Rev. 24:127-191.

Copeland, L.O., and M.B. McDonald. 1985. Principles of seed science and technology. 2nd ed. Burgess Publ. Co., Minneapolis, Minn.

Fareed, M., and M.M. Caldwell. 1975. Phenological patterns of two alpine tundra plant populations on Niwot Ridge, Colorado. Northwest Sci. 49:17-23.

Fenner, M. 1985. Seed ecology. Chapman and Hall, New York.

Grime, J.P. 1977. Evidence for the existence of three primary strategies in plants and its relevance to ecological and evolutionary theory. Amer. Nat. 111:1169-1194.

Grime, J.P. 1979. Plant strategies and vegetation processes. John Wiley and Sons, New York.

Grime, J.P., G. Mason, A.V. Curtis, J. Rodman, S.R. Band, M.A.G. Mowforth, A.M. Neal, and S. Shaw. 1981. A comparative study of germination characteristics in a local flora. J. Ecol. 69:1017-1059.

Harrington, J.F. 1973. Problems of seed storage. p. 251-264. In: W. Heydecker (ed.) Seed ecology. Pennsylvania Univ. Press, University Park.

Harper, J.L., P.H. Lovell, and K.G. Moore. 1970. The shapes and sizes of seeds. Annu. Rev. Ecol. Syst. 1:327-356.

Huston, M., and T.Smith. 1987. Plant succession: life history and competition. Amer. Nat. 130:168-198.

Johnson, P.L., and W.D. Billings. 1962. The alpine vegetation of the Beartooth Plateau in relation to cryopedogenic processes and patterns. Ecol. Monogr. 32:102-135.

MacMahon, J.A. 1980. Ecosystems over time: succession and other types of change. p. 27-58. In: R.H. Waring (ed.) Forests: fresh perspectives from ecosystem analysis. Oregon State Univ. Press, Corvallis.

MacMahon, J.A. 1981. Succession of ecosystems: a preliminary comparative analysis. p. 5-26. In: M.A. Hemstrom and J.R. Franklin (eds.) Successional research and environmental pollutant monitoring associated with biosphere reserves. Proc. 2nd U.S.-U.S.S.R. Symposium on Biosphere Reserves. Everglades Nat. Park, Fla.

Roach, D.A., and P.J. Marchand. 1984. Recovery of alpine disturbances: early growth and survival in populations of the native species, Arenaria groenlandica, Juncus trifidus, and Potentilla tridentata Arct. Alp. Res. 16:37-43.

Savile, D.B.0. 1972. Arctic adaptations in plants. Monogr. No. 6, Plant Res. Inst., Canadian Dep. Agr., Ottawa, Canada.

Sorenson, T. 1941. Temperature relations and phenology of the northeast Greenland flowering plants. Meddelelser on Gronland 125:1-305.

Spomer, G.G. 1964. Physiological ecology studies of alpine cushion plants. Physiol. Plant. 17:717-724.

USDA Forest Service. 1974. Seeds of woody plants in the United States. Agr. Handb. 450.

Webber, P.J., and J.D. Ives. 1978. Damage and recovery of tundra vegetation. Environ. Conserv. 5:171-182.

Young, J.A., and C.G. Young. 1986. Collecting, processing and germinating seeds of wildland plants. Timber Press, Portland, Ore.

\section{Moving in the near future?}

Please send us your change of address as soon as you can so you won't miss any issues of the Journal or Rangelands.

Please send your old address lable plus the following information to Society for Range Management: 1839 York Street, Denver, CO 80206.

Name
New Address
City
State

\section{ATTACH \\ OLD ADDRESS \\ LABEL HERE}

